\title{
AiMT
}

Advances in Military Technology

Vol. 12, No. 2 (2017), pp. 205-215

ISSN 1802-2308, eISSN 2533-4123

DOI 10.3849/aimt.01149

\section{Optimization of Defence Ability of Defence Structures by Using Monte Carlo Simulation}

\author{
D.H. Vu ${ }^{1 *}$, T. Baláž ${ }^{2}$ and F. Racek ${ }^{2}$ \\ ${ }^{1}$ Le Quy Don university, Ha Noi, Vietnam \\ ${ }^{2}$ Department of Weapons and Ammunition, University of Defence in Brno, Czech Republic
}

The manuscript was received on 20 September 2016 and was accepted after revision for publication on 24 October 2017.

\begin{abstract}
:
The article is focused on the calculation of defence structures' survival probability based on the Monte Carlo method. Besides, the blast resistance of defence structures is optimized due to the protection and expense requirements. The article also reviews properties of defence structures, characteristics of projectiles, and factors influencing on the structure's survival ability. To solve the problem, the computer simulation program has been developed and used for evaluating and optimizing the issue in various battle scenarios.
\end{abstract}

\section{Keywords:}

defence structure, blast resistance, Monte Carlo method, dispersed ammunition

\section{Introduction}

One of the most important tasks of military engineering soldiers is to design and develop a plan for the defensive work, according to the requirement of the commander. Defensive works including blast-resistant military buildings, trench lines, bunkers, shelters, etc., are deployed to prevent attacks. The defence ability of the military structure is characterized by its survival ability under the attack of opponent weapon systems. However, the higher the required blast resistance of the structure, the more economic cost, construction time, workforce and resource tend to increase. Thus, it is necessary to evaluate the survival ability of defence structures and select their relevant blast resistance level based on the actual battle scenarios. In reality, the evaluation can be conducted experimentally or by the computer simulation. Although the experiment requires very high cost and long execution time, the results are only suitable for some specific situations. Thus, it is advantageous to use computer simulations to solve the issue.

Besides, there is almost no published literature on the topic mentioned above. In this paper, a mathematical model for the prediction of structures' survival ability is developed based on the Monte Carlo method. The proper blast resistance is selected based

\footnotetext{
* Corresponding author: Le Quy Don university, 236 Hoang Quoc Viet, Ha Noi, Vietnam. Phone: +0849161878 88, E-mail:VuDucHieu.V2@gmail.com
} 
on the optimization method. Furthermore, the characteristics of defence structures and used weapon systems, as well as the interaction between them, are also presented.

\section{Characteristics of Defence Structures}

\subsection{Structural Characteristic}

A defence structure has three main parameters, which can influence its survival ability:

- Blast resistance $\left[\mathrm{kg} / \mathrm{cm}^{2}\right]$.

- $\operatorname{Location}(X, Y)[\mathrm{m}, \mathrm{m}]$.

- Area $\left[\mathrm{m}^{2}\right]$.

Blast resistance of a defence structure is the maximum expected pressure that the structure still withstands and keeps its integrity under given requirements. Immediately after the explosion, the created blast wave propagates from the explosive source through the environment and impacts on the structure. The blast wave can destroy the structure if its overpressure value is higher than the building's blast resistance. Conveniently, defence structures can be divided into five levels according to their blast resistance (Tab. 1).

Tab.1 Blast resistant level of structures

\begin{tabular}{|c|c|c|c|}
\hline Level & $\begin{array}{c}\text { Blast } \\
\text { resistance } \\
{\left[\mathbf{k g} / \mathbf{c m}^{2}\right]}\end{array}$ & $\begin{array}{c}\text { Typical } \\
\text { structure }\end{array}$ & Ability of resistance \\
\hline 1 & 0.5 & $\begin{array}{c}\text { Individual fire } \\
\text { pits, shelters }\end{array}$ & Fragments of warheads or projectiles \\
\hline 2 & 1.0 & Light bunkers & Small projectiles and mortars \\
\hline 3 & 3.0 & $\begin{array}{c}\text { Medium } \\
\text { bunkers }\end{array}$ & $\begin{array}{c}\text { Direct fire } 75 \mathrm{~mm} \text { cannons, indirect fire } \\
105 \mathrm{~mm} \text { guns, } 100 \text { lb bombs }\end{array}$ \\
\hline 4 & 4.0 & Heavy bunkers & $\begin{array}{c}\text { Direct fire } 90 \mathrm{~mm} \text { cannons, indirect fire of } \\
155 \mathrm{~mm} \text { guns, 250 lb bombs }\end{array}$ \\
\hline 5 & 15.0 & $\begin{array}{c}\text { Super heavy } \\
\text { bunkers }\end{array}$ & All conventional projectiles \\
\hline
\end{tabular}

A layout of defence structures is generated following the commander's tactics. However, if the arrangement of structures is too close to each other, it may occur that a projectile destroys more than two targets. In contrast, the tactical requirement may not be achieved as a result of too far distances among the structures. Therefore, to obtain effective tactics and reduce damage to the defence system, the structures must be arranged suitably.

\subsection{Economic Cost}

Costs have a significant influence on the ability to construct effective structures. In the paper, based on Vietnam people's army experiment, the costs of the military structures are shown in Tab. 2. 
The blast resistant level 5 represents the highest defence ability, but it also requires the largest expense and takes a lot of construction time. Therefore, the selection of relevant blast resistance level of the defence structure depends on the protection and expense requirements. It should be estimated carefully.

Tab. 2 The cost of military structures

\begin{tabular}{|c|c|c|}
\hline Blast resistant level & Blast resistance $\left[\mathbf{k g} / \mathbf{c m}^{\mathbf{2}}\right]$ & $\begin{array}{c}\text { Price per square meter } \\
{\left[\mathbf{U S} \mathbf{\$} / \mathbf{m}^{\mathbf{2}}\right]}\end{array}$ \\
\hline 1 & 0.5 & 250 \\
\hline 2 & 1.0 & 310 \\
\hline 3 & 3.0 & 450 \\
\hline 4 & 4.0 & 800 \\
\hline 5 & 15.0 & 1500 \\
\hline
\end{tabular}

\section{Characteristics of Weapons}

\subsection{Ballistic Dispersion of Weapons}

Regarding practice, an impact point of a projectile is scattered both in a line of fire and in a target range [1].

An impact point has two-dimensional normal distributions. The probability density function of the impact point is as follows:

$$
f(x, y)=\frac{1}{2 \pi \sigma_{\mathrm{x}} \sigma_{\mathrm{y}}} \exp \left(-\frac{1}{2}\left[\left(\frac{x-m_{\mathrm{x}}}{\sigma_{\mathrm{x}}}\right)^{2}+\left(\frac{x-m_{\mathrm{y}}}{\sigma_{\mathrm{y}}}\right)^{2}\right]\right) .
$$

In the military application, probable errors $\left(E_{\mathrm{x}}, E_{\mathrm{y}}\right)$ have been used popularly instead of standard deviations. Therefore, the probability density function can be written as bellow:

$$
\begin{aligned}
f(x, y) & =\frac{\rho^{2}}{\pi E_{\mathrm{x}} E_{\mathrm{y}}} \exp \left\{-\rho^{2}\left[\left(\frac{x-m_{\mathrm{x}}}{E_{\mathrm{x}}}\right)^{2}+\left(\frac{y-m_{\mathrm{y}}}{E_{\mathrm{y}}}\right)^{2}\right]\right\}, \\
& =\frac{\rho}{\sqrt{\pi} E_{\mathrm{x}}} \exp \left\{-\rho^{2}\left(\frac{x-m_{\mathrm{x}}}{E_{\mathrm{x}}}\right)^{2}\right\} \frac{\rho}{\sqrt{\pi} E_{\mathrm{y}}} \exp \left\{-\rho^{2}\left(\frac{y-m_{\mathrm{y}}}{E_{\mathrm{y}}}\right)^{2}\right\},
\end{aligned}
$$

where $(x, y)$ are the coordinates of the impact point, $\left(m_{\mathrm{x}}, m_{\mathrm{y}}\right)$ are the coordinates of the mean impact point, $\left(E_{\mathrm{x}}, E_{\mathrm{y}}\right)$ are the range probable error and deflection probable error, and the coefficient $\rho$ is 0.477 [2].

\subsection{Overpressure of Blast Calculation}

In the paper, the blast peak overpressure is estimated based on the scaled distance $Z$ introduced by Brode (1955) [3-5]: 


$$
P_{\text {so }}=\left\{\begin{array}{l}
\frac{1}{10}\left(\frac{6.7}{Z^{3}}+1\right) \mathrm{MPa}, \text { for } P_{\mathrm{so}}>1 \mathrm{MPa}, \\
\frac{1}{10}\left(\frac{0.975}{Z}+\frac{1.455}{Z^{2}}+\frac{5.85}{Z^{3}}-0.019\right) \mathrm{MPa}, \text { for } 0.01 \mathrm{MPa}<P_{\mathrm{so}}<1 \mathrm{MPa},
\end{array}\right.
$$

where $P_{\text {so }}$ is the peak overpressure value of blast and $Z$ is the scale distance calculated as bellow:

$$
\mathrm{Z}=R W^{-1 / 3},
$$

where $R$ is the distance between the impact point and the structure [m], $W$ is the TNT equivalent $[\mathrm{kg}]$.

\subsection{Firepower Usage}

Firepower usage is the selection of firepower, calibre, type of ammunition, and grid point of sight that can effectively damage to the defence structures. The calibre of ammunition is selected based on the assessment of opponent structure systems.

According to the grid point of sight, there are three ways of using firepower including shelling at a target point, shelling along lines and shelling on an area [1].

- Shelling at a target point is used by smart weapon systems. Due to using smart guidance systems, the smart weapon can destroy a target by only one time.

- Shelling along lines is executed by aircraft or unguided artillery units.

- Shelling on the area is used by artillery or mortar units. Because of less accuracy, artillery usually shells onto the defence structures with the change of sight point.

\section{Interaction between Blast Waves and Structures}

\subsection{Damage Radius}

Depending on the type of projectile, the destructive elements are various. The destruction can be caused by penetration of explosion, flammable materials toxins, etc.

The degree of damage depends on the type of used weapons, the resistant ability of building and the explosion range. Some structures collapse entirely, others have been damaged but could be restored. Frequently, the relationship between the degree of damage $P$ and the distance $R$ from the impact point to the target boundary is indicated in Fig. 4a:

- If $R<R_{1}$ then $P=1$, the structure is out of combat,

- If $R>R_{2}$ then $P=0$, the structure is preserved, where $R_{1}$ is the eliminated radius, $R_{2}$ is the safe radius.

The value of $R_{1}$ and $R_{2}$ are influenced by the direction of fire, the piercing depth of projectile, the orientation and the blast resistance level of the structure. The estimation $R_{1}$ and $R_{2}$ are complicated and unfeasible. Instead of determining exactly $R_{1}$, and $R_{2}$, it is assumed that the equivalent damage radius $R_{\mathrm{dr}}$ can be used and calculated as bellow:

$$
R_{\mathrm{dr}}=\frac{R_{1}+R_{2}}{2}
$$

Fig. $4 \mathrm{~b}$ shows the degree of damage $P$ and the equivalent damage radius $R_{\mathrm{dr}}$.

Each pair of structure and projectile has the equivalent damage radius (Fig. 5). $R_{\mathrm{dr}}$ is also calculated by solving Eq. (3). 
The destroy radius of the structure is calculated by Eq. (6).

$$
R_{\mathrm{ds}}=R_{\mathrm{st}}+R_{\mathrm{dr}},
$$

where $R_{\mathrm{st}}$ is the equivalent structure radius [m]; $R_{\mathrm{dr}}$ is the equivalent damage radius [m]; $R_{\mathrm{ds}}$ is the destroy radius $[\mathrm{m}]$.
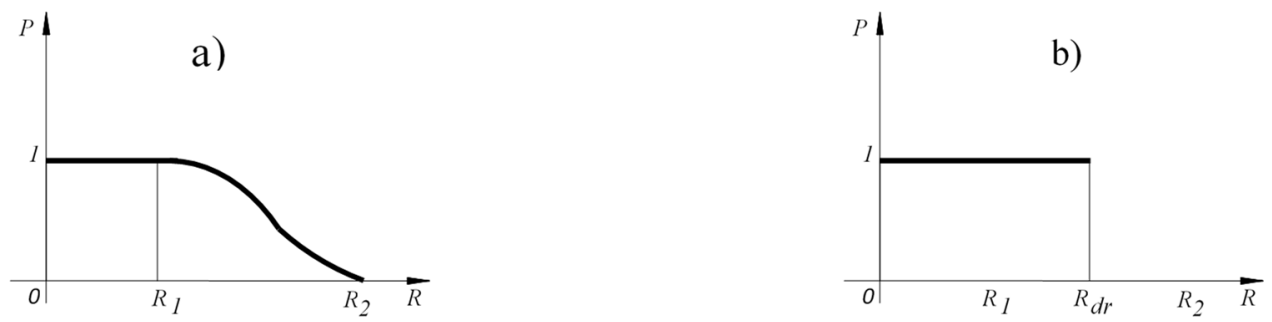

Fig. 4 Damage radius of structure

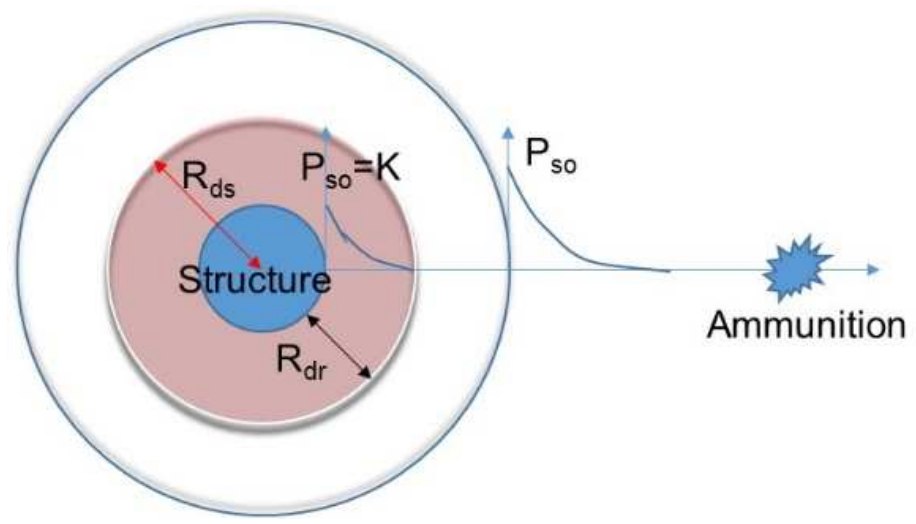

Fig. 5 Destroy radius of a structure

\subsection{Condition for Destroyed Structure}

The structure is destroyed if the distance between the impact point and the centre of the structure is smaller or equal than the destroyed radius $R$ ds:

$$
R \leq R_{\mathrm{ds}} \text {. }
$$

Because the distance $R$ is the aleatory variable, the survival probability of the structure still is the aleatory variable. This issue is complicated and cannot be solved by the analytical method. Thus, the Monte Carlo method is the effective method to solve the complex case.

\section{Simulation Results}

\subsection{Critical Optimization}

It is desirable to construct the defence structures with the minimal cost, the highest protection and the shortest required construction time. Unfortunately, these requirements cannot be achieved easily. For the above reasons, all building plans combining with predicted opponent fire usage should be assessed. To solve the issues, a GUI simulated 
program has been developed in Matlab environment. The program can solve the following optimization issues:

- According to required probability survival of the defence structures, the lowest blast resistant level of structures will be determined.

- According to minimal construction's cost and survivability requirements, the proper blast resistant level of structures will be determined.

\subsection{Simulation Examples}

Based on the plan of the commander, the proposal layout of the defensive work is designed and introduced in the Tab. 3 .

Tab. 3 List of defence structures

\begin{tabular}{|c|c|c|c|c|c|}
\hline No. & Name & Group & $\begin{array}{c}\text { Location } \\
X[\mathrm{~m}]\end{array}$ & $\begin{array}{c}\text { Location } \\
Y[\mathrm{~m}]\end{array}$ & $\begin{array}{l}\text { Area } \\
{\left[\mathbf{m}^{2}\right]}\end{array}$ \\
\hline 1 & Headquarter 1 & 1 & 200.6 & 120.2 & 70 \\
\hline 2 & Headquarter 2 & 1 & 426.9 & 158.9 & 70 \\
\hline 3 & Headquarter 3 & 1 & 359.3 & 49.6 & 70 \\
\hline 4 & Logistic & 2 & 410.7 & 35.4 & 22 \\
\hline 5 & Squad 1 & 2 & 110.2 & 60.6 & 25 \\
\hline 6 & Squad 2 & 2 & 67.3 & 111.6 & 25 \\
\hline 7 & Squad 3 & 2 & 112.8 & 147.7 & 25 \\
\hline 8 & Squad 4 & 2 & 337.2 & 82.6 & 25 \\
\hline 9 & Squad 5 & 2 & 290.0 & 54.3 & 25 \\
\hline 10 & Squad 6 & 2 & 311.4 & 16.0 & 25 \\
\hline 11 & Squad 7 & 2 & 394.6 & 130.4 & 25 \\
\hline 12 & Squad 8 & 2 & 369.4 & 176.8 & 25 \\
\hline 13 & Unit info & 2 & 258.3 & 114.9 & 30 \\
\hline 14 & Medic 1 & 3 & 209.0 & 89.8 & 50 \\
\hline 15 & Medic 2 & 3 & 499.4 & 147.3 & 50 \\
\hline 16 & Artillery P85-1 & 4 & 483.8 & 18.8 & 80 \\
\hline 17 & Artillery P85-2 & 4 & 500.0 & 111.1 & 80 \\
\hline 18 & Artillery P85-3 & 4 & 527.1 & 51.6 & 80 \\
\hline 19 & Artillery P85-4 & 4 & 471.2 & 186.4 & 80 \\
\hline 20 & Anti-aircraft Su23-1 & 5 & 426.6 & 72.7 & 75 \\
\hline 21 & Anti-aircraft Su23-2 & 5 & 210.6 & 148.3 & 75 \\
\hline 22 & Anti-aircraft Su23-3 & 5 & 275.4 & 134.3 & 75 \\
\hline 23 & Anti-tanks DKZ-1 & 6 & 84.5 & 77.7 & 20 \\
\hline 24 & Anti-tanks DKZ-2 & 6 & 93.4 & 125.8 & 20 \\
\hline
\end{tabular}




\begin{tabular}{|c|c|c|c|c|c|}
\hline No. & Name & Group & $\begin{array}{c}\text { Location } \\
\boldsymbol{X}[\mathbf{m}]\end{array}$ & $\begin{array}{c}\text { Location } \\
\boldsymbol{Y}[\mathbf{m}]\end{array}$ & $\begin{array}{c}\text { Area } \\
{\left[\mathbf{m}^{\mathbf{2}}\right]}\end{array}$ \\
\hline 25 & Anti-aircraft $12.7 \mathrm{~mm}-1$ & 6 & 144.6 & 101.7 & 20 \\
\hline 26 & Anti-aircraft $12.7 \mathrm{~mm}-2$ & 6 & 128.8 & 150.6 & 20 \\
\hline 27 & Anti-aircraft $12.7 \mathrm{~mm}-3$ & 6 & 352.0 & 152.2 & 20 \\
\hline 28 & Mortar 82-1 & 7 & 179.4 & 175.4 & 15 \\
\hline 29 & Mortar 82-2 & 7 & 187.3 & 65.5 & 15 \\
\hline
\end{tabular}

Assuming that the opponent uses the $152 \mathrm{~mm}$ howitzer to shell the battlefield at a distance of $12000 \mathrm{~m}$. The probable errors of the howitzer are evaluated by using firing table in the case of this range and shown in Tab. 4:

Tab. 4 The probable errors of $152 \mathrm{~mm}$ howitzer

\begin{tabular}{|c|c|c|c|c|}
\hline $\begin{array}{c}\text { Type of } \\
\text { charge }\end{array}$ & $\begin{array}{c}\text { Maximum } \\
\text { range fire } \\
{[\mathbf{m}]}\end{array}$ & $\begin{array}{c}\text { The calculated } \\
\text { distance } \\
\text { [m] }\end{array}$ & $\begin{array}{c}\text { The range } \\
\text { probable } \\
\text { error } \mathbf{E}_{\mathbf{x}} \text { [m] }\end{array}$ & $\begin{array}{c}\text { The deflection } \\
\text { probable } \\
\text { error } \mathbf{E}_{\mathbf{y}}[\mathbf{m}]\end{array}$ \\
\hline 0 & 20227 & 12000 & 37 & 4.2 \\
\hline 1 & 18500 & 12000 & 35 & 4.5 \\
\hline 2 & 14841 & 12000 & 41 & 5.7 \\
\hline 3 & 12990 & 12000 & 55 & 7.5 \\
\hline
\end{tabular}

According to Tab. 4, the charge number 1 is the most effective. The $152 \mathrm{~mm}$ howitzer has probable errors of $(35 \mathrm{~m}, 4.5 \mathrm{~m})$ in the case of using this charge. These probable errors are used for calculating the survival of the defence system. In the paper, the $152 \mathrm{~mm}$ howitzer uses $7.97 \mathrm{~kg}$ TNT equivalent projectiles.

The firepower usage of the weapon system is described in Tab. 5.

Tab. 5 Firepower usage

\begin{tabular}{|c|c|c|c|c|c|c|c|c|}
\hline Weapon & $\begin{array}{c}\boldsymbol{E}_{\mathbf{x}} \\
{[\mathbf{m}]}\end{array}$ & $\begin{array}{c}\boldsymbol{E}_{\mathbf{y}} \\
{[\mathbf{m}]}\end{array}$ & No. & $\begin{array}{c}\text { Direction } \\
{\left[{ }^{\circ}\right]}\end{array}$ & $\begin{array}{c}\boldsymbol{M}_{\mathbf{x}} \\
{[\mathbf{m}]}\end{array}$ & $\begin{array}{c}\boldsymbol{M}_{\mathbf{y}} \\
{[\mathbf{m}]}\end{array}$ & $\begin{array}{c}\text { Width } \\
{[\mathbf{m}]}\end{array}$ & $\begin{array}{c}\text { Length } \\
{[\mathbf{m}]}\end{array}$ \\
\hline $\begin{array}{c}152 \mathrm{~m} \\
\text { howitzer }\end{array}$ & 35 & 4.5 & 2 & 0 & 300 & 100 & 500 & 250 \\
\hline
\end{tabular}

Tab. 5 shows that the howitzer has the probable errors $\left(E_{\mathrm{x}}, E_{\mathrm{y}}\right)$ equal to $35 \mathrm{~m}, 4.5 \mathrm{~m}$; the direction of fire is 0 degree in the global coordinate system. The shelled area is the rectangular area $500 \times 250 \mathrm{~m}^{2}$ with the centre location $(300 \mathrm{~m}, 100 \mathrm{~m})$. As expected, the opponent will shell on the area by the grid point of sight $(5 \mathrm{~m} \times 19 \mathrm{~m})$ with equidistance firing control $\left(3 E_{\mathrm{x}} \times 3 E_{\mathrm{y}}\right)$. Fig. 6 illustrates the location of structures, the impact points, and the mean impact points. Each mean impact point is shelled by two projectiles. The battlefield is hit by $5 \times 19 \times 2=190$ projectiles in every test. The cross symbols illustrate the location of mean impact points while the black bullets are the place of the actual impact points. The red symbols depict the image of structures and the black symbols combined with $\mathrm{x}$ symbol describe the destroyed structure in the current test. The test results can change in the other tests. 
In order to find the optimal blast resistant level, firstly, the initial blast resistant level of the structures takes a value from 1 to 4 . Then, the structures' survival probability is evaluated based on the Monte Carlo method. The result is displayed in Tab. 6.

Because of equidistance firing control, the distribution of the impact points is similar to the uniform distribution. Thus, the survival probability of the defence structures in the same group is nearly similar (Tab. 6). Therefore, the proper blast resistant level of a structure can be assessed by estimating its group.

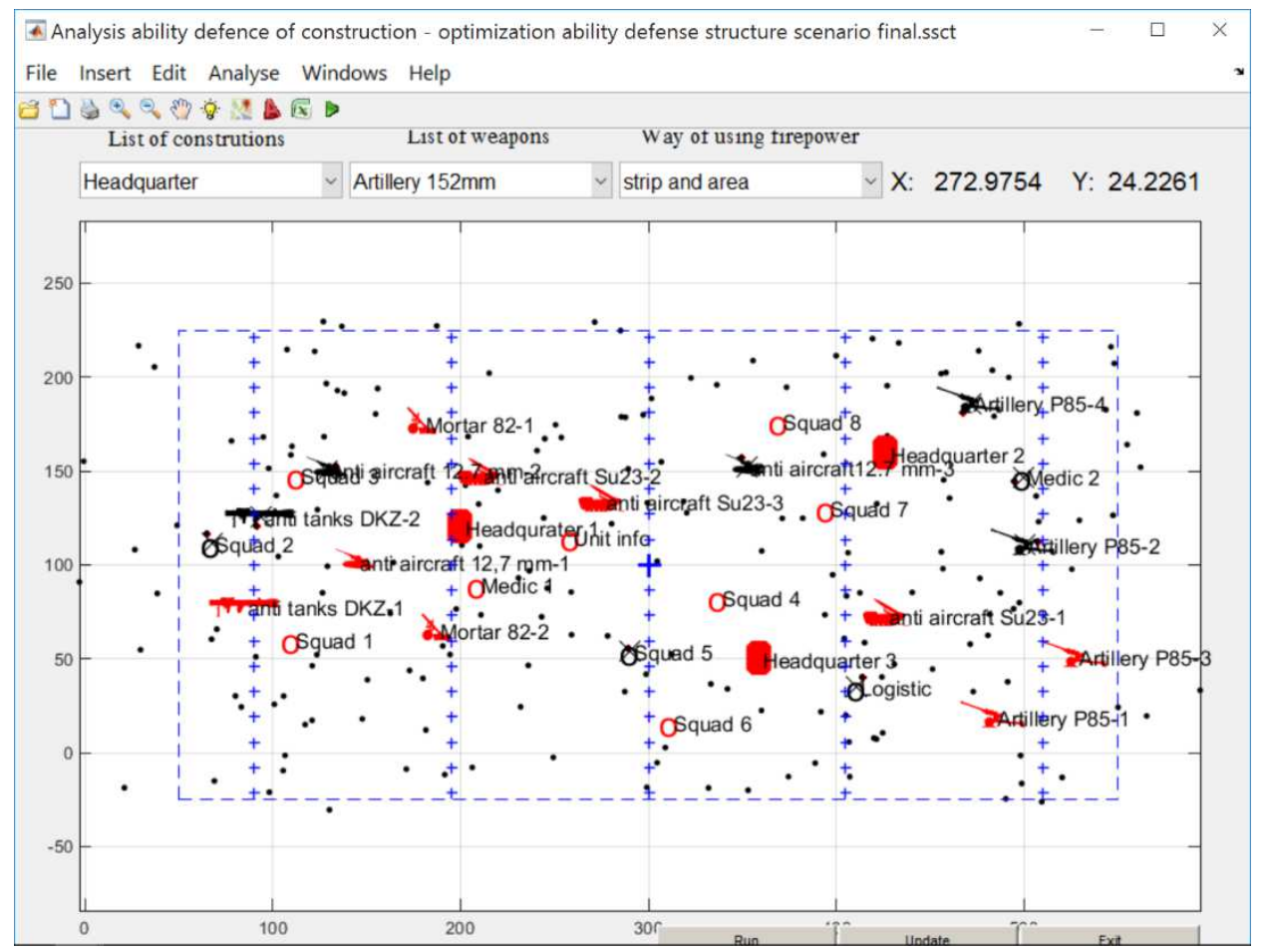

Fig. 6 Simulation scenario

Tab. 6 Survival probability of structures

\begin{tabular}{|c|c|c|c|c|c|}
\hline No. & Name & Level 1 & Level 2 & Level 3 & Level 4 \\
\hline 1 & Headquarter 1 & 0.42 & 0.59 & 0.70 & 0.73 \\
\hline 2 & Headquarter 2 & 0.43 & 0.53 & 0.72 & 0.72 \\
\hline 3 & Headquarter 3 & 0.40 & 0.60 & 0.72 & 0.74 \\
\hline 4 & Logistic & 0.51 & 0.69 & 0.83 & 0.85 \\
\hline 5 & Squad 1 & 0.53 & 0.69 & 0.79 & 0.84 \\
\hline 6 & Squad 2 & 0.64 & 0.75 & 0.87 & 0.89 \\
\hline 7 & Squad 3 & 0.54 & 0.69 & 0.84 & 0.85 \\
\hline 8 & Squad 4 & 0.51 & 0.65 & 0.82 & 0.84 \\
\hline
\end{tabular}




\begin{tabular}{|c|c|c|c|c|c|}
\hline No. & Name & Level 1 & Level 2 & Level 3 & Level 4 \\
\hline 9 & Squad 5 & 0.51 & 0.72 & 0.78 & 0.79 \\
\hline 10 & Squad 6 & 0.53 & 0.68 & 0.81 & 0.86 \\
\hline 11 & Squad 7 & 0.53 & 0.69 & 0.83 & 0.85 \\
\hline 12 & Squad 8 & 0.47 & 0.73 & 0.82 & 0.86 \\
\hline 13 & Unit info & 0.54 & 0.67 & 0.85 & 0.84 \\
\hline 14 & Medic 1 & 0.45 & 0.63 & 0.79 & 0.78 \\
\hline 15 & Medic 2 & 0.48 & 0.63 & 0.73 & 0.82 \\
\hline 16 & Artillery P85-1 & 0.41 & 0.53 & 0.71 & 0.69 \\
\hline 17 & Artillery P85-2 & 0.41 & 0.58 & 0.70 & 0.76 \\
\hline 18 & Artillery P85-3 & 0.53 & 0.72 & 0.84 & 0.86 \\
\hline 19 & Artillery P85-4 & 0.52 & 0.69 & 0.81 & 0.87 \\
\hline 20 & Anti-aircraft Su23-1 & 0.39 & 0.57 & 0.67 & 0.74 \\
\hline 21 & Anti-aircraft Su23-2 & 0.40 & 0.56 & 0.71 & 0.73 \\
\hline 22 & Anti-aircraft Su23-3 & 0.40 & 0.55 & 0.69 & 0.71 \\
\hline 23 & Anti-tank DKZ-1 & 0.57 & 0.73 & 0.86 & 0.86 \\
\hline 24 & Anti-tank DKZ-2 & 0.57 & 0.71 & 0.83 & 0.87 \\
\hline 25 & Anti-aircraft 12.7 mm-1 & 0.54 & 0.71 & 0.85 & 0.88 \\
\hline 26 & Anti-aircraft 12.7 mm-2 & 0.56 & 0.68 & 0.87 & 0.87 \\
\hline 27 & Anti-aircraft 12.7 mm-3 & 0.55 & 0.74 & 0.83 & 0.88 \\
\hline 28 & Mortar 82-1 & 0.55 & 0.72 & 0.84 & 0.86 \\
\hline 29 & Mortar 82-2 & 0.57 & 0.70 & 0.85 & 0.87 \\
\hline
\end{tabular}

Secondly, the initial level of all structures is set to 1 . The cost and the structures' survival probability is calculated and shown on Tab. 7.

Tab. 7 shows that the average survival ability probability of the defence system is 0.50 ; the total building cost is about US\$ 308750 .

Finally, by changing the integer value of the blast resistant level from 1 to 4 , the proper value of blast resistant can be determined based on given requirements. Fundamentally, this is an optimization issue, which is solved by the optimal analysis [6-8].

\section{a) Optimization Issue 1}

Discovering the level of groups satisfies the following requirements:

- The total building cost is minimal.

- The level is integer number and has a value from 1 to 4 .

- The group 1 (headquarter) has the ability survival equal to or more than 0.7 .

- The average survival ability probability of the system is equal to or more than 0.6. The result of the issue is calculated by using the optimization tool and introduced in Tab. 8. 
Tab. 7 The survival probability of structures

\begin{tabular}{|c|c|c|c|c|c|c|}
\hline Group & Amount & $\begin{array}{c}\text { Initial } \\
\text { level }\end{array}$ & $\begin{array}{c}\text { Area } \\
{\left[\mathbf{m}^{\mathbf{2}}\right]}\end{array}$ & $\begin{array}{c}\mathbf{C o s t} \\
{\left[\mathbf{U S} \mathbf{\$} \mathbf{m}^{\mathbf{2}} \text { ] }\right.}\end{array}$ & $\begin{array}{c}\text { Total group cost } \\
{[\mathbf{U S} \mathbf{\text { ] }}]}\end{array}$ & $\begin{array}{c}\text { Survival } \\
\text { probability }\end{array}$ \\
\hline 1 & 3 & 1 & 70 & 250 & 52500 & 0.42 \\
\hline 2 & 10 & 1 & 25 & 250 & 62500 & 0.53 \\
\hline 3 & 2 & 1 & 50 & 250 & 25000 & 0.46 \\
\hline 4 & 4 & 1 & 80 & 250 & 80000 & 0.47 \\
\hline 5 & 3 & 1 & 75 & 250 & 56250 & 0.40 \\
\hline 6 & 5 & 1 & 20 & 250 & 25000 & 0.56 \\
\hline 7 & 2 & 1 & 15 & 250 & 75000 & 0.56 \\
\hline & & & & & 308750 & 0.50 \\
\hline
\end{tabular}

Tab. 8 The result of issue 1

\begin{tabular}{|c|c|c|c|c|c|c|c|}
\hline & $\begin{array}{c}\text { Group } \\
\mathbf{1}\end{array}$ & $\begin{array}{c}\text { Group } \\
\mathbf{2}\end{array}$ & $\begin{array}{c}\text { Group } \\
\mathbf{3}\end{array}$ & $\begin{array}{c}\text { Group } \\
\mathbf{4}\end{array}$ & $\begin{array}{c}\text { Group } \\
\mathbf{5}\end{array}$ & $\begin{array}{c}\text { Group } \\
\mathbf{6}\end{array}$ & $\begin{array}{c}\text { Group } \\
\mathbf{7}\end{array}$ \\
\hline Level & 3 & 2 & 1 & 1 & 1 & 2 & 1 \\
\hline $\begin{array}{c}\text { Survival } \\
\text { ability }\end{array}$ & 0.71 & 0.70 & 0.46 & 0.47 & 0.40 & 0.71 & 0.56 \\
\hline
\end{tabular}

According to the blast resistant level result, the total building cost of the defence structures is equal to US\$ 371750 ; the average survival probability of the system is 0.61 . However, although the system can be built with the lowest cost, the survival ability of group 4 and group 5 is still too low. It is considered that it is better if these important groups have the survival probability more than $50 \%$. To achieve it, group 4 and group 5 should reach level 2. The final proper result is shown in Tab. 9:

Tab. 9 Final result of issue 1

\begin{tabular}{|c|c|c|c|c|c|c|c|}
\hline & $\begin{array}{c}\text { Group } \\
\mathbf{1}\end{array}$ & $\begin{array}{c}\text { Group } \\
\mathbf{2}\end{array}$ & $\begin{array}{c}\text { Group } \\
\mathbf{3}\end{array}$ & $\begin{array}{c}\text { Group } \\
\mathbf{4}\end{array}$ & $\begin{array}{c}\text { Group } \\
\mathbf{5}\end{array}$ & $\begin{array}{c}\text { Group } \\
\mathbf{6}\end{array}$ & $\begin{array}{c}\text { Group } \\
\mathbf{7}\end{array}$ \\
\hline Level & 3 & 2 & 1 & 2 & 2 & 2 & 1 \\
\hline $\begin{array}{c}\text { Survival } \\
\text { ability }\end{array}$ & 0.71 & 0.70 & 0.46 & 0.63 & 0.56 & 0.71 & 0.56 \\
\hline
\end{tabular}

In this case, the total construction cost of the defence system is US\$ 404450 .

\section{b) Optimization Issue 2}

Finding the level of groups fulfils the following requirements:

- The total building price is less than US\$ 500000.

- The level is integer number and has a value from 1 to 4 .

- Group 1 (headquarter group) has the ability survival more than or equal to 0.7.

- The average survival ability of system is maximized.

The results are calculated and displayed in Tab. 10: 
Tab. 10 Result of issue 2

\begin{tabular}{|c|c|c|c|c|c|c|c|}
\hline & $\begin{array}{c}\text { Group } \\
\mathbf{1}\end{array}$ & $\begin{array}{c}\text { Group } \\
\mathbf{2}\end{array}$ & $\begin{array}{c}\text { Group } \\
\mathbf{3}\end{array}$ & $\begin{array}{c}\text { Group } \\
\mathbf{4}\end{array}$ & $\begin{array}{c}\text { Group } \\
\mathbf{5}\end{array}$ & $\begin{array}{c}\text { Group } \\
\mathbf{6}\end{array}$ & $\begin{array}{c}\text { Group } \\
\mathbf{7}\end{array}$ \\
\hline Level & 3 & 3 & 2 & 2 & 3 & 3 & 3 \\
\hline $\begin{array}{c}\text { Survival } \\
\text { ability }\end{array}$ & 0.71 & 0.83 & 0.63 & 0.63 & 0.69 & 0.85 & 0.85 \\
\hline
\end{tabular}

\section{Conclusion}

The aim of the paper is to describe using a Monte Carlo method to evaluate the survival probability of defence structures. Using various scenarios, the relevant survival probability of the system and the relevant blast resistance of the defence structures can be evaluated by using the optimization method. In this paper, the examples of assumed defence structures are also depicted with two optimization issues.

A simulation program has been developed to solve this problem. It is a suitable and low-cost solution to evaluate the survival ability of defence structure system in many cases.

In order to reach a more accurate result, the blast-wave load should be calculated using the American standard UFC 3-340-02, 2008 in future work. Otherwise, it is necessary to integrate digital maps and build a real-time scenario in this program.

\section{References}

[1] U. S. DEPARTMENT OF THE ARMY. Tactics, Techniques, and Procedures for Field Artillery Manual Cannon Gunnery, FM 6-40 [cited 2016-07-11]. 1999. Available from: <http://armypubs.army.mil>.

[2] WEE, Y.L. Predicting the accuracy of unguided artillery projectiles [PhD Thesis], [cited 2016-08-21]. 2016. Naval Postgraduate School. Available from: $<$ http://calhoun.nps.edu/handle/10945/50581>.

[3] NGO, T., MENDIS, P., GUPTA, A. and RAMSAY, J. Blast Loading and Blast Effects on Structures - An Overview. Electronic Journal of Structural Engineering - special issue, 2007, vol. 7, p. 76-91. ISSN 1443-9255.

[4] ACOSTA, P.F. Overview of UFC 3-340-02 Structures to Resist the Effects of Accidental Explosions. In: Structures Congress 2011 [cited 2016-07-03]. Reston, VA: American Society of Civil Engineers, 2011, p. 1454-1469. ISBN 978-0-78441171-1. DOI 10.1061/41171(401)127.

[5] BRODE, H.L. Numerical Solutions of Spherical Blast Waves. Journal of Applied Physics, 1955, vol. 26, no. 6, p. 766-775. ISSN 0021-8979. DOI 10.1063/1.085.

[6] MATLAB. Optimization Toolbox ${ }^{T M}$ User's Guide [cited 2016-08-01]. 2016. Available from: <https://www.mathworks.com/help/pdf_doc/optim/optim_tb.pdf $>$.

[7] QUIRK, T.J. Excel 2010 for Engineering Statistics. Springer, 2014, 246 p. ISBN 978-3-319-02829-3. DOI 10.1007/978-3-319-02830-9.

[8] HARMON, M. Step-By-Step Optimization with Excel Solver-The Excel Statistical Master. Excel Master Series, 2012. ISBN 978-1-937159-15-3. 